\title{
Cierre de comunicaciones bucosinusales con colgajos palatinos
}

\section{Closure of oral sinus communications with palatal flaps}

\section{Autoras}

\author{
Marisa Raffo \\ Especialista en Cirugia y Traumatologia BMF \\ Prof. Adjunto de Cirugia BMF II FOUDELAR \\ Asistente de Cirugia de la FOUCU
}

Entregado para revisión: 9 de febrero de 2016 Aceptado para publicación: 22 de mayo de 2016

\section{Resumen}

Las comunicaciones bucosinusales (CBS) son una condición patológica que se caracteriza por la presencia de una solución de continuidad entre la cavidad bucal y el seno maxilar.

Una vez que se ha instalado una CBS es deseable cerrar este defecto, evitando así la infección del seno maxilar y posibles dificultades en la deglución, fonación y masticación.

Se han propuesto diferentes tratamientos para su resolución, algunos no quirúrgicos y otros quirúrgicos. Los quirúrgicos pueden realizarse desplazando tejidos locales, regionales o injertando.

El objetivo de este trabajo es mostrar la utilidad del cierre plásticos local con colgajo palatino. Para ello se muestran dos casos clínicos y se realizó una revisión de la bibliografía con la intensión de clarificar sus ventajas y desventajas.

Palabras claves: comunicación buco sinusal, colgajo palatino.

\footnotetext{
Abstract

Oroantral communication $(\mathrm{OAC})$ is a pathological condition characterized by the presence of an abnormal communication between the maxillary sinus and the oral cavity.

Once an OAC has established, the closure of this defect is desired in order to avoid infection of the maxillary sinus, and possible difficulties in swallowing, speaking and chewing.

Several treatments have been suggested for this condition, both surgical and non surgical. Surgical treatments consist of relocating local or regional tissue and grafting.

The purpose of this work is to show the effectiveness of local plastic closure using a palatal flap. Two clinical cases are presented and a revision of literature was performed in order to clarify its advantages and disadvantages.
}

Key words: oroantral communication, palatal flap 


\section{INTRODUCCIÓN}

Una CBS es una solución de continuidad entre el seno maxilar y la cavidad bucal. Las CBS afectan por definición tres planos, que son la mucosa sinusal o membrana de Schneider, hueso maxilar superior o palatino y el mucoperiostio bucal (Ries Centeno, 1987; Gay Escoda (2011).

El tratamiento de una CBS, no siempre implica la reconstrucción de los tres planos, pero si requiere de la observación de una serie de factores que se detallan a continuación:

a) Estado general del paciente.

b) El tamaño de la perforación.

c) Localización de la comunicación.

d) Estado de los bordes y márgenes de la perforación

e) Infección en el alvéolo y en el seno maxilar

f) Integridad del coágulo en el defecto óseo.

g) Tiempo transcurrido desde la comunicación hasta el cierre.

h) Continuidad o no de la arcada dentaria y tejido óseo.

i) Resencia o no de dientes en el maxilar.

j) Presencia de cuerpos extraños dentro del seno maxilar.

Se debe tener presente que el tratamiento quirúrgico debe realizarse sobre tejidos mucosos y óseos sanos, y de existir patología sinusal debe ser resuelta en forma previa o simultanea a la plastia, (Ries Centeno,1987; Lazow et al 1999; Navarro, 2004; Gay Escoda (2011). Para lograr el cierre nos valemos de tejidos locales o distantes. Estos son seleccionados de manera que tengan una correcta irrigación y que cubran sin tensión el defecto (Ries Centeno, 1987 ; Navarro, 2004; Gay Escoda, 2011).

El colgajo palatino rotado fue descrito por Ashley en1939 y se talla a lo largo de los vasos palatinos mayores, incluyendo mucosa, submucosa y periostio palatino del lado de la CBS (Ries Centeno, 1987; Navarro, 2004; Gay Escoda, 2011).

El cierre de una CBS con colgajo palatino está indicado cuando ésta se ubica sobre el reborde alveolar a nivel del primer molar y segundo premolar, y aquellas situadas sobre la bóveda palatina (Lazow et al, 1999; Navarro, 2004; Kale et al, 2010)

La mucosa palatina es de tipo masticatorio, está firmemente unida al periostio del paladar óseo, y en la parte posterior su epitelio se encuentra perforado por diminutos orificios, por donde desembocan las glándulas salivales palatinas (Gutierrez et al, 2012 ).
La submucosa consta de bandas fibrosas que fijan la mucosa al periostio formando pequeños compartimentos; ocupados por lóbulos de grasa en el sector anterior al primer molar y por glándulas salivales posteriores a éste (Ries Centeno, 1987).

Entre las bandas fibrosas, la grasa y las glándulas de la submucosa se abren paso los troncos vasculares y nerviosos palatinos mayores (Gutierrez et al, 2012).

\section{CASO CLÍNICO 1}

Hombre de 29 años, que consulta por presencia de mal gusto y exudado intrabucal después de la extracción de una pieza en cuadrante dos. Niega antecedentes médicos generales. Al exámen local se observa una CBS sobre reborde alveolar superior izquierdo a nivel de primer molar.

Al realizar maniobra de Valsalva se produce la salida de exudado purulento, figura no. 1 .

El estudio por imágenes confirma una sinusitis maxilar izquierda, posiblemente secundaria a fistula oroantral por extracción del primer molar

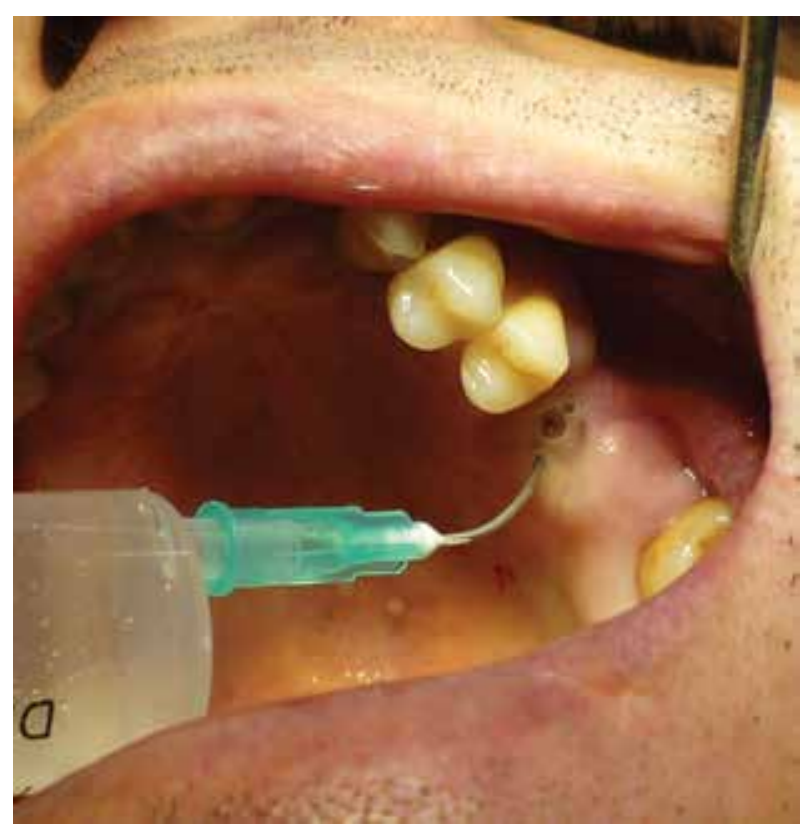

Fig 1.

\section{Los colgajos palatinos no interfieren en}

la profundidad del vestíbulo y su rica

vascularización les permite una buena cicatrización. 


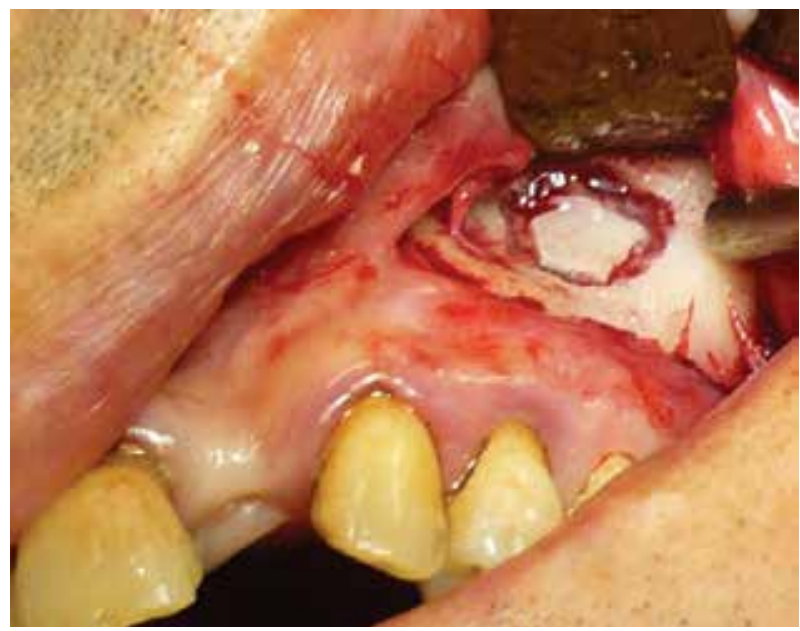

Fig 2.

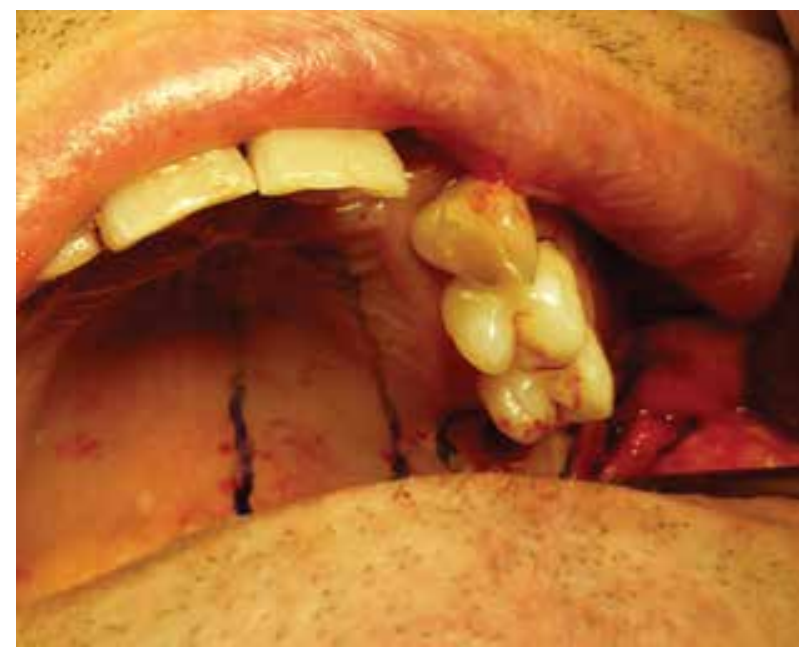

Fig 4.

Se procede a realizar lavados sinusales con clohorexidina a $0,12 \%$ y con suero fisiológico, de manera de mejorar las condiciones del seno hasta la coordinación para realizar un Cadwel Luc (figura 2), con cierre plástico de la fistula en dos planos.

El primer plano se realizó con un colgajo marginal y el segundo plano con un colgajo palatino rotado (figura 3 y 4 )

Se realiza el diseño del colgajo con lápiz demográfico, trazando una recta paralela a la línea media del paladar separada de la misma unos 3 milímetros, comenzando 5 milímetros por delante de la unión del paladar duro con el blando.

Ésta línea recta se curva lateralmente hacia el lado afectado en el momento en que alcanza la región del canino, para seguir en dirección otra vez, hacia la zona posterior, paralela a la cresta alveolar, pero a unos 4 milímetros de distancia.

Es fundamental tener presente la dirección sagital de la arteria palatina mayor en el diseño del colgajo

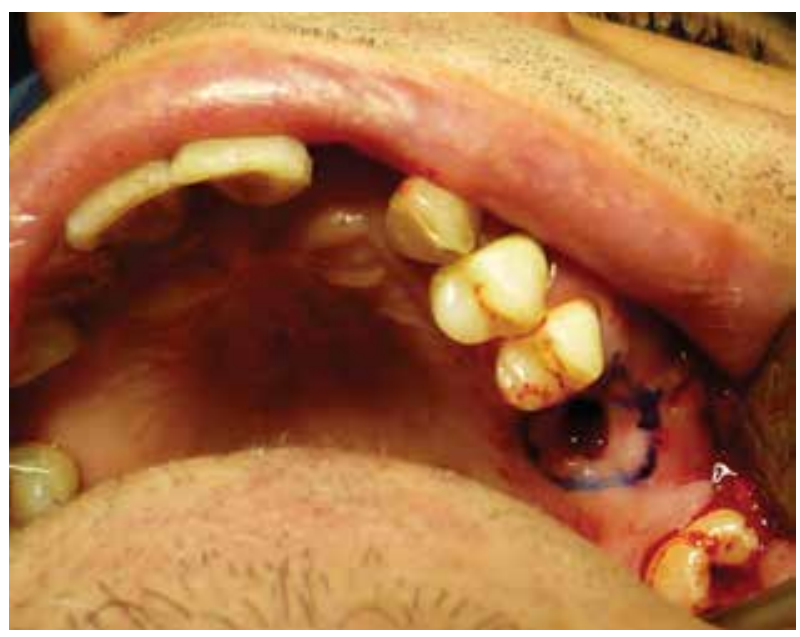

Fig 3.

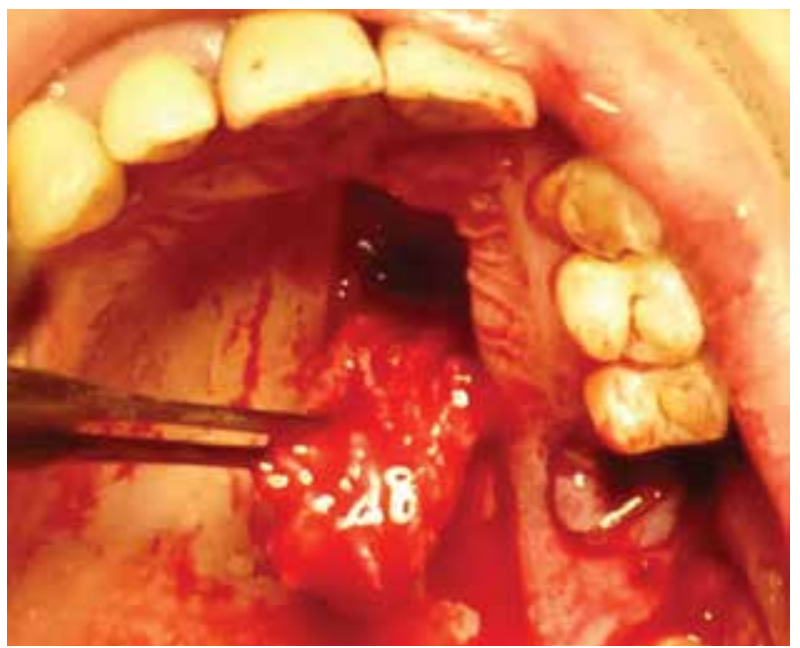

Fig 5.

y las características de la mucosa y submucosa en la disección del mismo (Ries Centeno, 1987; Lazow 1999; Lee et al, 2002; Navarro, 2004),

El colgajo se realiza con bisturí Bard Parker y hoja No.15. En cuanto a su espesor la mayoría involucran mucosa, submucosa y periostrio, aunque algunas de ellos pueden ser de espesor parcial, debiendo en estos casos evitar comprometer la irrigación de los tejidos (Ito \& Hara, 1980; Ries Centeno, 1987; Navarro, 2004; Gay Escoda, 2011).

Wassmund (Ries Centeno, 1987) traza una serie de normas a las cuales debe ajustarse el cirujano para lograr éxito en sus intervenciones plásticas:

1- el ancho del colgajo debe ser dos tercios de su largo. Colgajos de longitud desproporcionada a su ancho se necrosan en su extremo libre.

2- debe tener un espesor adecuado.

3- su base debe ser mayor que su vértice. 


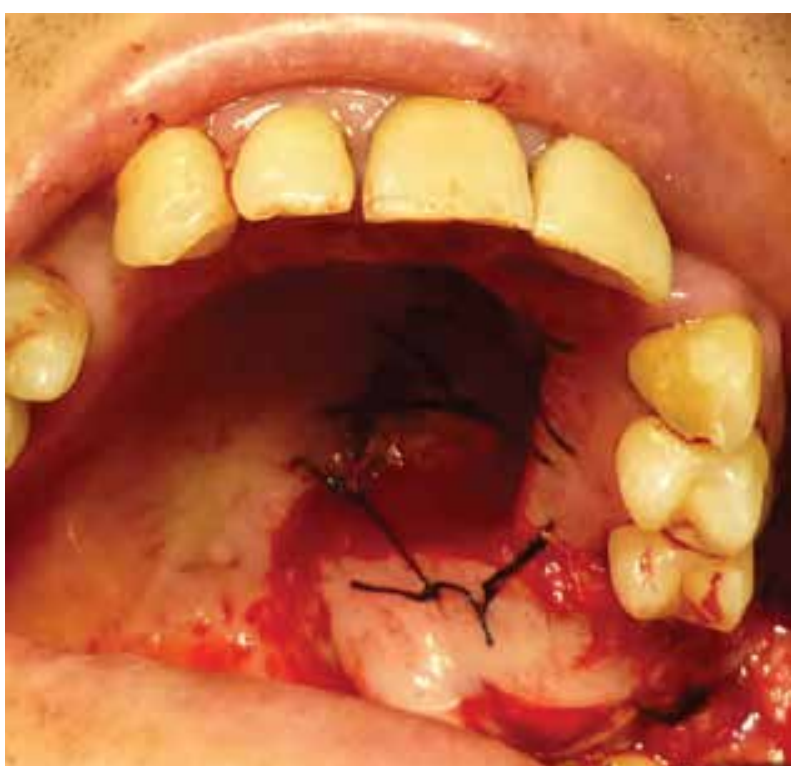

Fig 6.

Luego de tallarlo el colgajo, debe alcanzarse el plano subperiostico con sindesmótomo, continuando el decolamiento mucoperiostico con legra. Las firme adherencia de la mucosa y submucosa determinan la dificultad de esta etapa (Ries Centeno, 1987; Lazow, 1999; Lee et al 2002; Navarro, 2004). Figura No.5

Luego se procede a la rotación sobre su pedículo para ocluir el defecto.

Esta rotación no debe ser excesiva, evitando así el riesgo de interrumpir el aporte sanguíneo por estrangulamiento del vaso arterial (Ries Centeno 1987; Gay Escoda, 2011)

Finalmente se sutura el colgajo con puntos simples a los bordes del defecto con sutura de seda 3.0 o 4.0. La zona dadora permanece cruenta, algunos autores promueven colocar cemento quirúrgico,o suturar gasa yodoformada con eugenol. Figura No.6

El hueso palatino expuesto cierra por segunda intención (figura No.7) no crea ningún problema funcional, consiguiéndose una reepitelización completa indistinguible de la fibromucosa palatina normal entre 3-5 semanas (Navarro, 2004; Hernando et al, 2010).

\section{CASO CLIÍNICO 2}

Paciente de sexo femenino de 38 años de edad, sin antecedentes médicos a destacar, fumadora moderada, la cual consulta por recidiva de comunicación

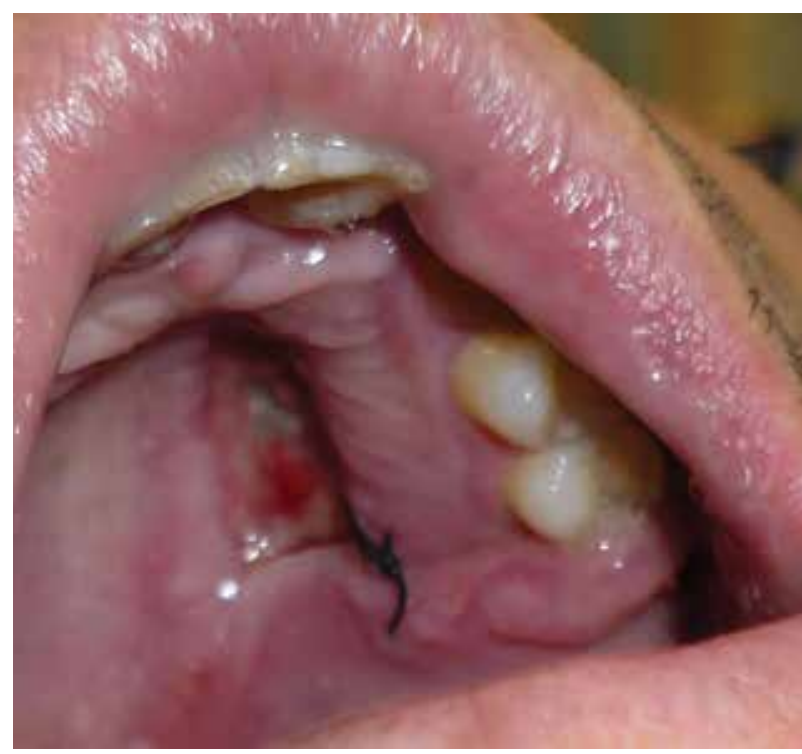

Fig 7.

bucosinusal. A la paciente se le había realizado, un mes y medio atrás, una cirugía radical de seno maxilar y un cierre plástico de comunicación bucosinusal. En el momento de la consulta se constata comunicación bucosiusal, la cual se encuentra bien a mesial de la brecha. fig 8 .

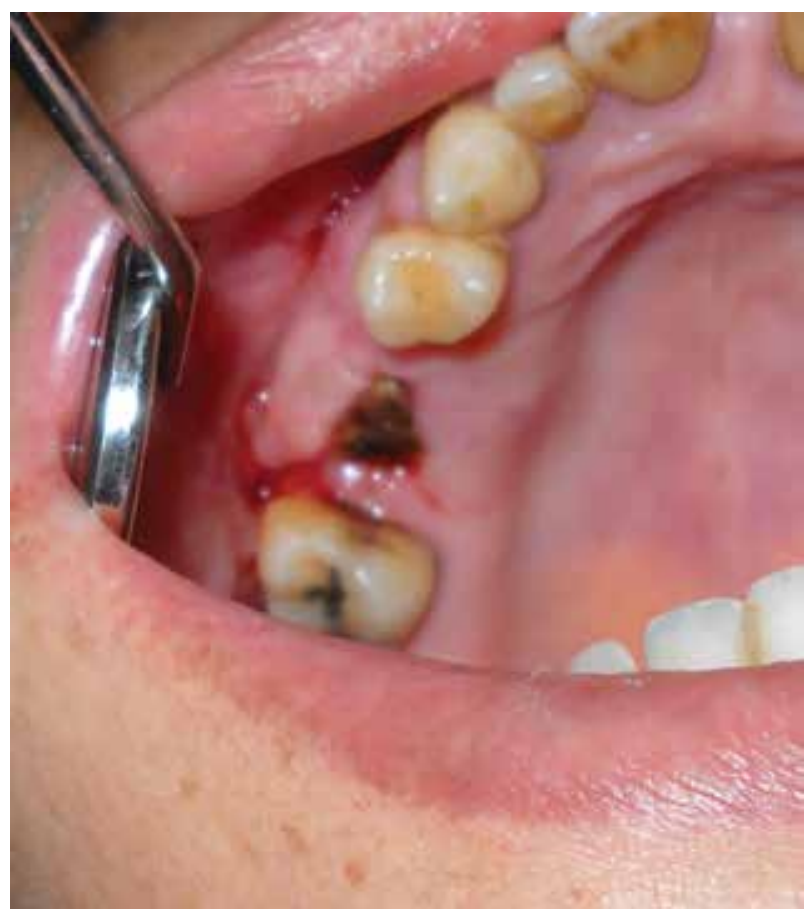

Fig 8. 
La paciente relataba sentir pasaje fundamentalmente de líquidos desde la cavidad bucal a al seno, no presentaba sintomatología sinusal. La maniobra de Valsalva resultó positiva.

La paciente iba a realizar su rehabilitación mediante una prótesis parcial removible, y como la comunicación se topografiaba en la zona correspondiente a la pieza 25 se decidió realizar el nuevo cierre de la comunicación mediante colgajo palatino. En este

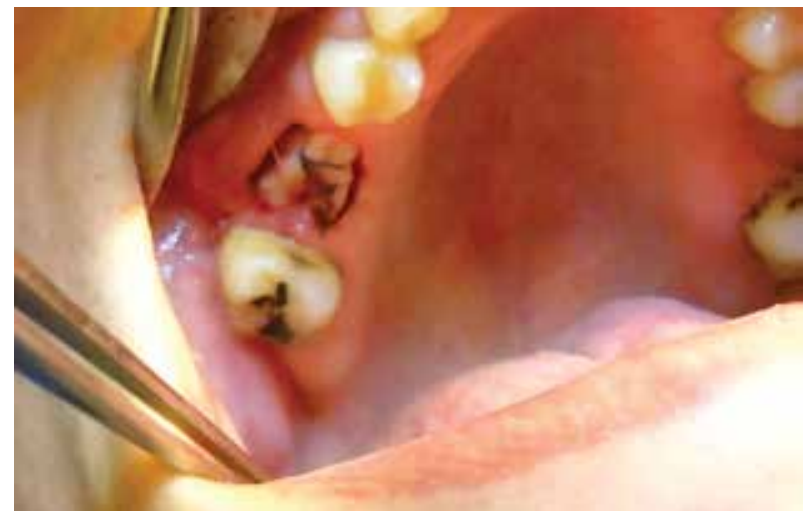

Fig 9.

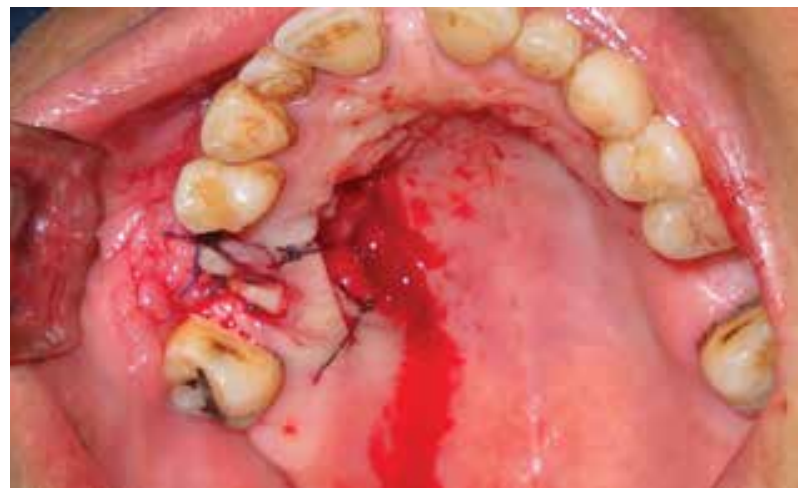

Fig 11.

\section{Los colgajos palatinos presentan} algunas desventajas: su grosor $y$ consistencia, tendencia a retraerse y dejan una área cruenta en el paladar que debe cerrar por segunda intención. caso se optó por realizar el cierre en dos planos mediante un colgajo marginal el cual se cubrió con un colgajo palatino tunelizado bajo un puente de tejido alveolar. Fig 9,10,11. En este caso la zona dadora fue protegida con gasa yodoformada la cual se suturo.Fig. 12.

A los 20 días del postoperaatorio la zona presentaba el aspecto de la fig. 13

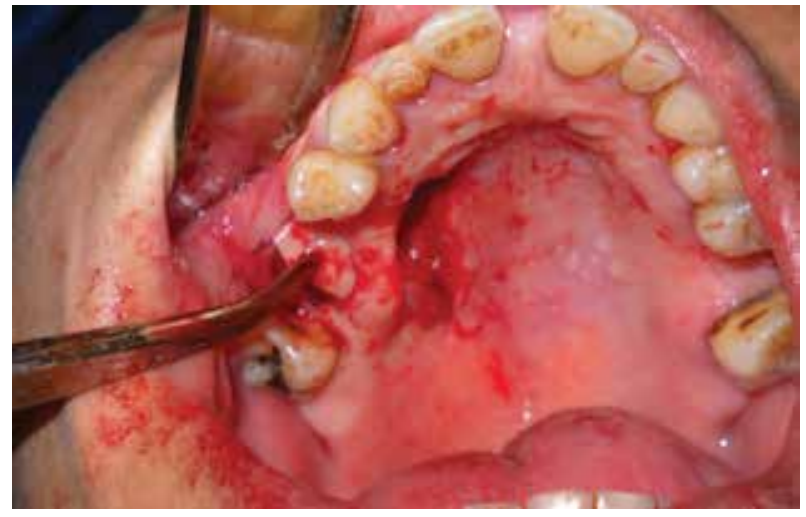

Fig 10.

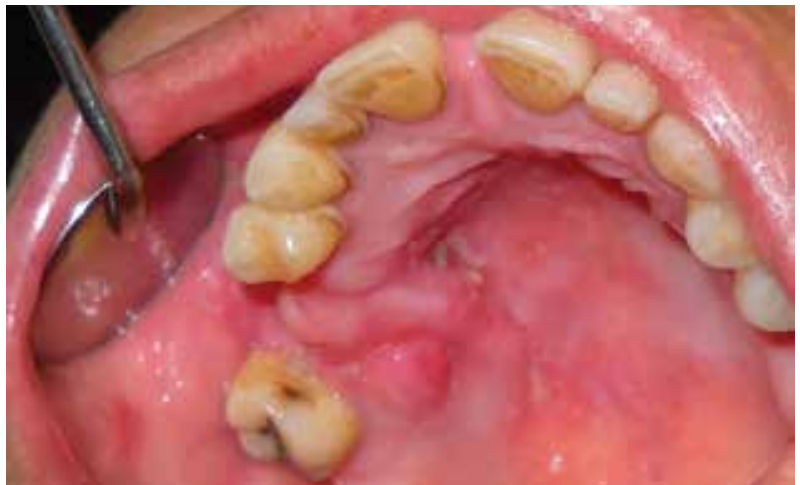

Fig 12

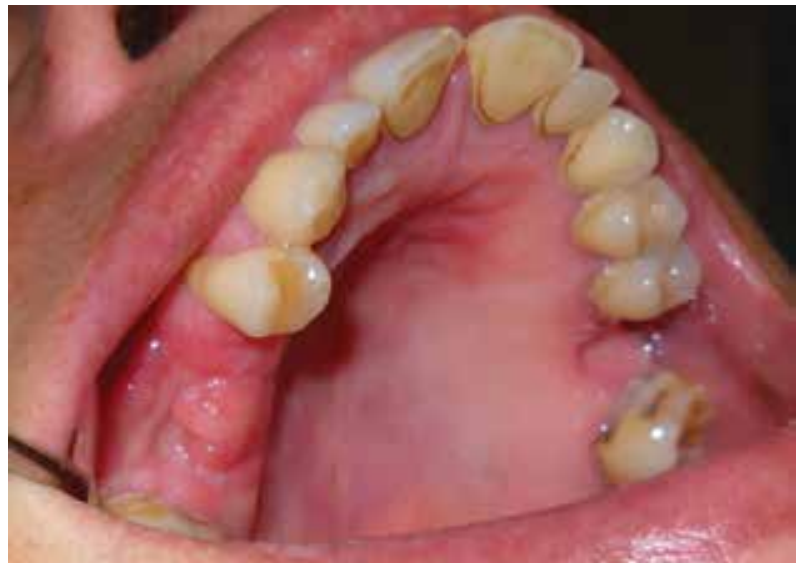

Fig 13. 


\section{DISCUSIÓN}

Las CBS son frecuentes en cirugía Bucomaxilofacial, está indicado tratarlas ya que a punto de partida de ellas se pueden producir complicaciones infecciosas como la sinusitis, y/o dificultades funcionales en la deglución, fonación y masticación

Se debe arribar a un diagnóstico minucioso, conociendo en qué condiciones se encuentra el seno maxilar, el tamaño, localización de la CBS así como estado de los tejidos peri-lesionales. De este balance surgirá el plan de tratamiento que combine la menor morbilidad con la mayor tasa de éxito.

Se han propuesto diferentes tratamientos para su resolución, algunos de ellos no quirúrgicos, como el uso de prótesis que permiten el cierre mientras están aplicadas.

Otra posibilidad para el cierre son las plastias, en este caso se debe determinar que tejidos serán utilizados. La primera elección son los colgajos locales, donde nos valemos de tejidos vecinos a la perforación, los cuales son desplazados en grado variable, del sito donde asientan hasta el lugar donde se necesitan.

El colgajo palatino rotado es una alternativa que puede emplearse cuando se pretende realizar el cierre de una CBS localizada sobre el reborde alveolar de primer molar o segundo premolar y/o bóveda palatina.

Dentro de las ventajas de esta técnica figura su capacidad para mantener la profundidad del vestíbulo bucal, hecho importante en pacientes que deban ser rehabilitados mediante prótesis posteriormente.

También la posibilidad de obtener tejido de buen grosor con una rica vascularización, características éstas que lo hacen muy seguro en el cierre de CBS. Para evitar el riesgo de comprometer la perfusión sanguínea del colgajo al hacer la rotación, y el dolor postoperatorio dado por el paladar denudado del sitio donante algunos autores han descrito modificaciones de la técnica.

Kruger (1984) sugiere la escisión des una cuña en forma de $\mathrm{V}$ en la zona de la rotación para evitar el pliegue de mucosa y el consiguiente compromiso vascular.

Choukas (1974) deja un puente de tejido próximo al reborde alveolar, y pasa el colgajo palatino por debajo, disminuyendo así la tensión en la zona de rotación y facilitando la retención del colgajo.

Ito y Hara (1980) describen la disección en dos partes del colgajo palatino, obteniendo un colgajo de tejido submucoso, que es rotado para cubrir el defecto y un colgajo de mucosa palatina que cubre la zona donante.

De esta manera consiguen un colgajo bien vascularizado y elástico que permite ser rotada sin tensión para cubrir el defecto. Por otro lado la zona dadora es cubierta por el colgajo mucoso, lo que proporciona mayor comodidad al paciente y una curación temprana de la zona

Hendersen (1974), Herbert (1974) y luego Gullane y Arena en 1977, y James (1980) describen el colgajo palatino en isla. En esta modificación el colgajo mantiene el contacto con la zona dadora a través de una pequeña base mucosa y de la arteria palatina mayor.

Es una técnica que proporciona un colgajo con un excelente volumen e irrigación, evitando la congestión venosa asociada a la rotación del colgajo palatino. Proporciona un espesor importante de tejido, asegurando un cierre poco friable (Ries Centeno, 1987; Lehman, 1995; Lazow et al, 1999; Lee et al, 2002; Kale et al, 2010; Gay Escoda, 2011).

Entre sus desventajas se menciona que es un colgajo de difícil decolamiento, que tiene tendencia a encogerse cuando se eleva del hueso.

$\mathrm{Su}$ grosor y consistencia, pueden dificultrar el reposicionamiento sobre el defecto. Dejan una zona denudada en el paladar que debe cerrar por segunda intención (Lazow et al, 1999; Lee et al, 2002; Gay Escoda, 2011).

\section{CONCLUSIONES}

La utilización del colgajo palatino para el cierre de CBS ha demostrado ser una técnica muy segura, de fácil realización y que no produce alteraciones importantes de la anatomía de la región a largo plazo, por lo que creemos que debe ser tenida en cuenta al momento de realizar plastias en la zona premolar molar del maxilar superior

\section{REFERENCIAS}

Awang MN. (1988). Closure of oroantral fistula. Int J Oral Maxillofac Surg; 17(2): 110-15.

Lee JJ, Kok SH, Chang HH, Yang PJ, Hahn LJ, Kuo YS. (2002) Repair of oroantral communications in the third molar region by random palatal flap. Int J Oral Maxillofac Surg; 31: 677-80.

Choukas NC.(1974). Modified palatal flap technique for closure of oroantral fistulas. J Oral Surg; 32:112-113. 
Dergin G, Gurler G, Gursoy B.(2007). Modified connective tissue flap: a new approach to closure of an oroantral fistula. Br J Oral Maxillofac Surg; 45: 251-2.

Galvis A, Alexander J. (2011). Colgajos locales y pediculados en el manejo dlas comunicaciones y fístulas oroantrales. Rev Med [internet] [citado 2016 Jun 3]; 19(2): 217-225. Disponible en: http://www.scielo.org.co/ scielo.php?script $=$ sci_arttext\&pid $=$ S0121-52562011000200008\&lng $=$ en.

García Linares SA. (2004). El colgajo rotatorio palatino: una alternativa en la cicatrización por primera intención en el paladar. Odontol Sanmarquina [internet] [citado 2016 Jun 3]; 8(1): 6-9. Disponible en: http:// revistasinvestigacion.unmsm.edu.pe/index.php/odont/article/view/3365

Gay Escoda C. (2011). Cirugía bucal. Barcelona: Océano; 2011. 2 v.

Godoy E, Godoy A, Godoy P (2011). Cierre de fístula oroantral con injerto óseo y con rotación y avance de colgajo palatino. Rev Otorrinolaringol Cir Cabeza Cuello [internet] [citado 2016 Jun 3]; 71(3): 257-262. Disponible en: http://www.scielo.cl/scielo.php?script=sci_arttext\&pid=S0718-48162011000300011\&lng=es. Gullane PJ, Arena S. (1977). Palatal island flap for reconstruction of oral defects. Arch Otolaryngol;103(10):598-599.

Gutierrez J, Domínguez M, Escudero P, García JM, Vicente M, Manchini T, Acevedo N. (2012). Anatomía cráneofacial. $2^{\mathrm{a}}$ ed. Montevideo: Universidad de la República.

Haas R, Watzak G, Baron M, Tepper G, Mailath G, Watzek G. (2003). A preliminary study of monocortical bone grafts for oroantral fistula closure. Oral Surg Oral Med Oral Pathol Oral Radiol Endod; 96(3):263-6. Hendersen, D.(1974). Palatal island flap in the closure of oro-antral fistulae. Br J Oral Surg; 12(2):141-46. Herbert DC. (1974). Closure of a palatal fistula using mucoperiosteal island flap. Br J Plast Surg; 27(4): 332-36.

Hernando J, Gallego L, Junquera L, VIllarreal P. (2010). Oroantral communications: a retrospective analysis. Med Oral Patol Oral Cir Bucal; 15(3): e499-503.

Ito T, Hara H.(1980). A new technique for closure of oroantral fistula. J Oral

Surg; 38(7):509-12.

James RB. (1980). Surgical closure of large oroantral fistulas using a palatal island flap. J Oral Surg; 38(8): 591-95.

Janakarajah N. (1983). The island flap in the closure of palatal and cheek defect. J. Pergigian Universiti Malaya;1:47-51.

Kale TP, Urolagin S, Khurana V, Kotrashetti SM (2010). Treatment of oroantral fistula using palatal flap: a case report and technical note. J Int Oral Health [internet] [citado 2016 Jun 3]; 2(3): 77-82. Disponible en: http://ispcd.org/userfiles/rishabh/12.\%20Dr\%20Tejraj\%20F.pdf

Kruger GO.(1984). Textbook of oral and maxillofacial surgery. 6th ed. St. Louis: Mosby. p. 291-93.

Lazow SK.(1999). Surgical management of the oroantral fistula: flap procedures. Oper Tech Otolaryngol Head Neck Surg; 10(2): 148-52.

Lee JJ, Kok SH, Chang HH, Yang PJ, Hahn LJ, Kuo YS. (2002). Repair of oroantral communications in the third molar region by random palatal flap. Int J Oral Maxillofac Surg; 31(6):677-80.

Lehman JA.(1995). Closure of palatal fistulas. Oper Tech Plastic Reconstr Surg; 2(4): 255-62.

Navarro Vila C.(2009). Tratado de cirugía oral y maxilofacial. $2^{\mathrm{a}}$ ed. Madrid: Arán. 3 v.

Ries Centeno G.(1987). Cirugía bucal: patología, clínica y terapéutica. 9a ed. Buenos Aires: El Ateneo.

Salins PC, Kishore SK.(1996). Anteriorly based palatal flap for closure of large oroantral fistula. Oral Surg Oral Med Oral Pathol Oral Radiol Endod; 82(3): 253-6 